\title{
Influence of the Mediterranean Outflow on the Isotopic Composition of Neodymium in Waters of the North Atlantic
}

\author{
D. J. Piepgras and G. J. Wasserburg \\ The Lunatic Asylum of the Charles Arms Laboratory, Division of Geological and Planetary Sciences, California Institute of \\ Technology, Pasadena, California 91125
}

\begin{abstract}
The isotopic composition of neodymium in the water column of the eastern North Atlantic near the Strait of Gibraltar has been determined for several depths. The data show that the Mediterranean outflow results in a significant shift in $\varepsilon_{\mathrm{Nd}}(0)$ toward more radiogenic values of ${ }^{143} \mathrm{Nd} /{ }^{144} \mathrm{Nd}$ in the water column at a 1000-m depth. This corresponds to a depth in the neighborhood of the salinity maximum associated with the Mediterranean outflow. The core of the Mediterranean outflow gives $\varepsilon_{\mathrm{Nd}}(0)=-9.8$, as compared to $\varepsilon_{\mathrm{Nd}}(0) \approx-12$ in overlying and underlying waters, demonstrating that the Mediterranean waters are distinct from the Atlantic. From mixing considerations we estimate that pure Mediterranean waters have $\varepsilon_{\mathrm{Nd}}(0) \approx-6$. Possible sources of this relatively radiogenic Nd could be from drainage of young continental terranes or the injection of remobilized Nd from deep-sea sediments that have a young radiogenic volcanic component. New data from a depth profile in the western Atlantic is presented. Comparison of $\mathrm{Nd}$ data for the eastern North Atlantic with that for the western North Atlantic shows fundamental differences in the water column structures for $\varepsilon_{\mathrm{Nd}}(0)$. While both regions show a pronounced maximum in $\varepsilon_{\mathrm{Nd}}(0)$, the western basin maximum occurs at the near surface rather than at $1000 \mathrm{~m}$. In addition, deep waters of the eastern basin are found to be more radiogenic than the western basin. These differences indicate several sources of isotopically distinct Nd in the North Atlantic. The deep waters of the North Atlantic $(>1000 \mathrm{~m})$ have the lowest values of $\varepsilon_{\mathrm{Nd}}(0)$ measured in the oceans. We believe that the source of these low $\varepsilon_{\mathrm{Nd}}(0)$ values, which we associate with North Atlantic deep water, is either from freshwater drainage off the Precambrian shields of North America and Asia into the Arctic Ocean or from the injection of 'older,' continentally derived REE from deep-sea sediments. Sm and Nd concentrations are found to increase with depth and $\varepsilon_{\mathrm{Nd}}(0)$ changes with depth, indicating both vertical and lateral transport processes from different sources. This suggests a surface source of Nd and injection of REE into the water column from deepsea sediments or large-scale bottom currents with high REE concentrations.
\end{abstract}

\section{INTRODUCTION}

In this study we have examined the effect of the Mediterranean outflow on the isotopic composition of neodymium in the water column of the eastern North Atlantic. Because of the very long half-life of ${ }^{147} \mathrm{Sm}\left(t_{1 / 2}=1.06 \times 10^{11}\right.$ years $)$ and the short cycling time of the rare earth elements (REE) in the oceans, compared to mixing between the oceans, the ratio ${ }^{143} \mathrm{Nd} /{ }^{144} \mathrm{Nd}$ is variable in seawater. This variation reflects the ${ }^{143} \mathrm{Nd} /{ }^{144} \mathrm{Nd}$ ratio in the source terranes that supply the REE to the oceans. The ${ }^{143} \mathrm{Nd} /{ }^{144} \mathrm{Nd}$ ratio is used as a tracer for studying the transport of REE in the oceans and may be used for studying the origin of different water masses. A summary of the observations and current ideas in this field may be found in an article by Piepgras and Wasserburg [1982]. The Nd isotopic data presented in this paper will be given in units of $\varepsilon_{\mathrm{Nd}}(0)$.

$$
\varepsilon_{\mathrm{Nd}}(0)=\left[\frac{\left({ }^{143} \mathrm{Nd} /{ }^{144} \mathrm{Nd}\right)_{\text {measured }}}{0.511847}-1\right] \times 10^{4}
$$

where 0.511847 is the present-day ${ }^{143} \mathrm{Nd} /{ }^{144} \mathrm{Nd}$ ratio in a chondritic reservoir [DePaolo and Wasserburg, 1976; Jacobsen and Wasserburg, 1980].

Recent studies have clearly established that there are distinct differences in the Nd isotopic composition between the different oceans [Piepgras et al., 1979; Piepgras and

\section{Copyright 1983 by the American Geophysical Union.}

Paper number 3 C0468.

0148-0227/83/003C-0468\$05.00
Wasserburg, 1980; Goldstein and O'Nions, 1981; Piepgras and Wasserburg, 1982]. In addition to the interocean $\mathrm{Nd}$ isotopic variations, smaller but distinct variations occur within individual ocean basins. Results from previous studies of $\mathrm{Nd}$ isotopic measurements for vertical profiles in the Sargasso Sea and the Central Pacific [Piepgras and Wasserburg, 1980, 1982] are shown in Figure $1 a$ and $c$. In addition to these results, additional data has been obtained for another Atlantic profile at station $30\left(36^{\circ} \mathrm{N}, 62^{\circ} \mathrm{W}\right)$ and are shown in Figure $1 b$. The results for station 30 indicate a uniform deepwater isotopic composition of $\varepsilon_{\mathrm{Nd}}(0) \approx-14$, in agreement with data for the Sargasso Sea. All of these profiles indicate a source of REE at the surface which is distinct from that for the respective deep waters. This demonstrates lateral as well as vertical transport of the REE. In the Pacific profile the bottom water at this station has been identified, on the basis of its $\mathrm{Nd}$ composition, to have spread northward from the southern ocean [Piepgras and Wasserburg, 1982]. Isotopic heterogeneity in the water column is not ubiquitous, however. The southern ocean in the vicinity of the Drake Passage has uniform ${ }^{143} \mathrm{Nd} /{ }^{144} \mathrm{Nd}$ in the water column, corresponding to $\varepsilon_{\mathrm{Nd}}(0) \approx-9$ and a linear gradient in $\mathrm{Nd}$ concentration, leading to the conclusion that it is isotopically, but not chemically, well mixed [Piepgras and Wasserburg, 1982]. Results of these various studies indicate that it should be possible to monitor the effects of injection of REE on the water column in regions where the injected REE can be characterized isotopically.

We have chosen to look at the effects of the Mediterranean outflow on the Nd isotopic composition in the water column of the eastern North Atlantic. The Mediterranean outflow 


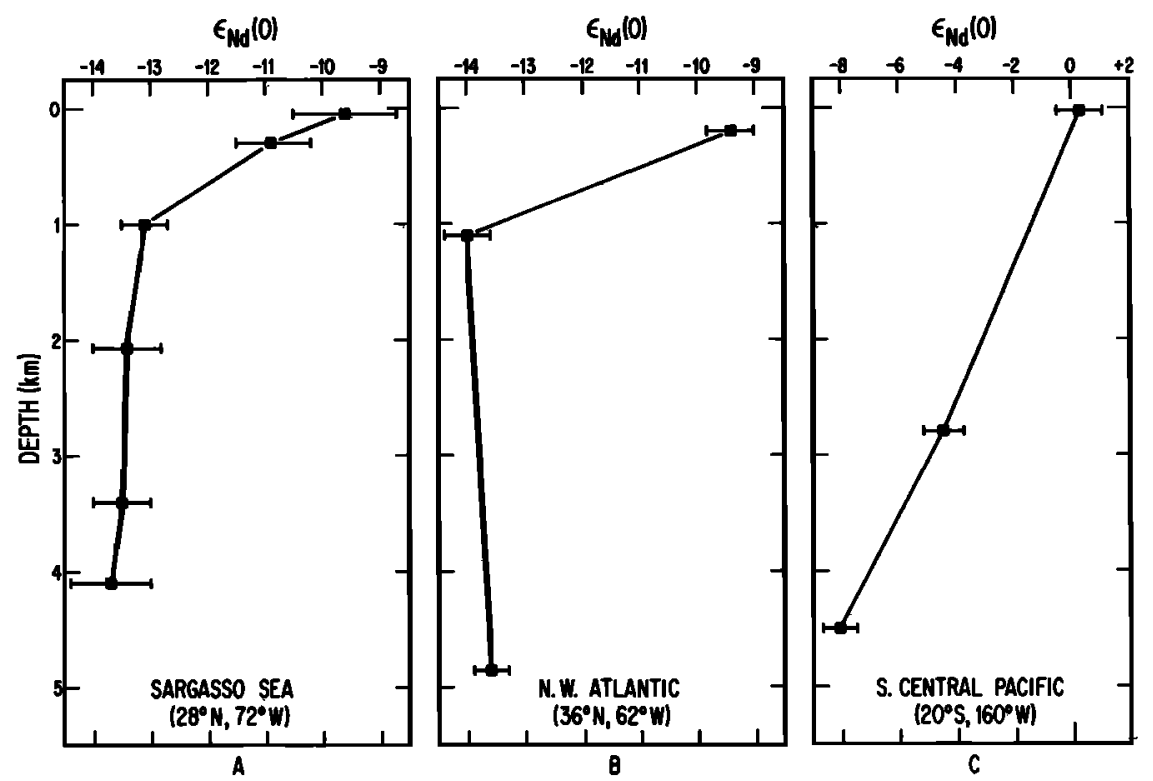

Fig. 1. $\varepsilon_{\mathrm{Nd}}(0)$ as a function of depth in the (A) Sargasso Sea (Piepgras and Wasserburg, 1980], (B) western North Atlantic at A-II, 109-1, station 30 (this study), and (C) south central Pacific [Piepgras and Wasserburg, 1982]. The Sargasso Sea data is a composite of several closely spaced stations. The location given in the figure for these samples is the approximate mean position of all stations from the Sargasso Sea.

has a profound influence on the temperature and salinity characteristics of the Atlantic. The high evaporation rate in the Mediterranean Sea produces water masses with salinities greater than $38 \%$. Some of this dense, saline water spills into the Atlantic over the Gibraltar sill at a rate of about $1.04 \times$ $10^{6} \mathrm{~m}^{3} / \mathrm{s}$ [Tchernia, 1980]. This outflow is replaced by an inflow of less saline Atlantic surface water at a rate of about $1.11 \times 10^{6} \mathrm{~m}^{3} / \mathrm{s}$, which balances the outflow and net evaporation losses of water in the Mediterranean. The dense Mediterranean outflow water moves downward along the continental slope, mixing with Atlantic water as it sinks to a depth of $\sim 1000 \mathrm{~m}$, where it reaches water of the same density. At this level it spreads out across the Atlantic, resulting in an intermediate-depth salinity maximum, which is the characteristic feature of the core of upper North Atlantic deep water [Dietrich et al., 1980]. The Mediterranean outflow also results in the Atlantic having a warmer median temperature than the Pacific [Knauss, 1978]. The influx of Atlantic water is the largest source of water to the Mediterranean, and it might be expected that this component would dominate the Nd isotopic character of the Mediterranean. If the isotopic composition of $\mathrm{Nd}$ in the outflowing Mediterranean water can be distinguished from $\mathrm{Nd}$ in the Atlantic water it flows into, then a source of isotopically distinct $\mathrm{Nd}$ to the Mediterranean would be required. This condition would allow simple modeling of the REE transport

TABLE 1. Sample Locations and Results of Sm and Nd Measurements

\begin{tabular}{|c|c|c|c|c|c|}
\hline $\begin{array}{c}\text { Depth, } \\
\text { m }\end{array}$ & $\begin{array}{c}\mathrm{Nd}, \\
10^{-12} \mathrm{~g} / \mathrm{g} \\
\end{array}$ & $\begin{array}{c}\mathrm{Sm}, \\
10^{-12} \mathrm{~g} / \mathrm{g} \\
\end{array}$ & $\frac{{ }^{147} \mathrm{Sm}}{{ }^{144} \mathrm{Nd}}$ & $\frac{{ }^{143} \mathrm{Sm}}{{ }^{144} \mathrm{Nd}}$ & $\varepsilon_{\mathrm{Nd}}(0)$ \\
\hline \multicolumn{6}{|c|}{ A-II, 109-I, Station $95\left(36^{\circ} 17^{\prime} 41^{\prime \prime} N, 10^{\circ} 02^{\prime} 27^{\prime \prime} W\right)$, Eastern North Atlantic } \\
\hline $\begin{array}{r}\text { Sur- } \\
\text { face } \\
200 \\
500 \\
800 \\
1000 \\
1000 \\
1150 \\
1300 \\
2000 \\
3000 \\
4000\end{array}$ & $\begin{array}{l}1.80 \\
2.01 \\
2.26 \\
2.48 \\
2.34 \\
2.35 \\
2.61 \\
2.49 \\
2.46 \\
2.84 \\
3.33\end{array}$ & $\begin{array}{l}0.376 \\
0.417 \\
0.473 \\
0.528 \\
0.519 \\
-\overline{032} \\
0.533 \\
0.498 \\
0.556 \\
0.644\end{array}$ & $\begin{array}{l}0.126 \\
0.125 \\
0.126 \\
0.128 \\
0.134 \\
-\overline{127} \\
0.129 \\
0.122 \\
0.118 \\
0.117\end{array}$ & $\begin{array}{l}0.511264 \pm 33 \\
0.511208 \pm 19 \\
0.511240 \pm 30 \\
0.511304 \pm 28 \\
0.511348 \pm 29 \\
0.511334 \pm 20 \\
0.511251 \pm 28 \\
0.511253 \pm 26 \\
0.511221 \pm 20 \\
0.511208 \pm 25 \\
0.511245 \pm 22\end{array}$ & $\begin{array}{r}-11.4 \pm 0.7 \\
-12.5 \pm 0.4 \\
-11.9 \pm 0.6 \\
-10.6 \pm 0.5 \\
-9.8 \pm 0.6 \\
-10.0 \pm 0.4 \\
-11.7 \pm 0.5 \\
-11.6 \pm 0.6 \\
-12.2 \pm 0.4 \\
-12.5 \pm 0.5 \\
-11.8 \pm 0.4\end{array}$ \\
\hline 650 & $\begin{array}{c}A-I I, 1 \\
5.16\end{array}$ & Station 101 & $15^{\prime \prime} N, 0$ & $\begin{array}{c}\text { (W), Gulf of Cao } \\
0.511340 \pm 20\end{array}$ & $-9.9 \pm 0.4$ \\
\hline $\begin{array}{r}200 \\
1100 \\
4850\end{array}$ & $\begin{array}{c}A-I I, 109-I \\
1.96 \\
2.60 \\
9.01\end{array}$ & $\begin{array}{c}30\left(36^{\circ} I\right. \\
- \\
-\end{array}$ & $\begin{array}{l}61^{\circ} 58^{\prime} 2 \\
- \\
-\end{array}$ & $\begin{array}{c}\text { Western North } A \\
0.511365 \pm 20 \\
0.511128 \pm 21 \\
0.511153 \pm 16\end{array}$ & $\begin{array}{r}-9.4 \pm 0.4 \\
-14.0 \pm 0.4 \\
-13.6 \pm 0.3\end{array}$ \\
\hline
\end{tabular}

The ${ }^{143} \mathrm{Nd} /{ }^{144} \mathrm{Nd}$ ratios were determined in samples spiked with ${ }^{150} \mathrm{Nd}$ and normalized to ${ }^{146} \mathrm{Nd} /$ ${ }^{142} \mathrm{Nd}=0.636151$. Reported errors are two standard deviations from the mean. $2 \sigma$ errors for concentration measurements are $\sim 0.05 \%$ for $\mathrm{Nd}$ and $\sim 0.1 \%$ for $\mathrm{Sm}$. 
TABLE 2. Hydrographic Data for Eastern North Atlantic Samples

\begin{tabular}{|c|c|c|c|c|c|}
\hline Depth, m & Salinity, \%o & $\mathrm{O}_{2}, \mu M / \mathbf{k g}$ & $\begin{array}{c}\text { Phosphate, } \\
\mu M / \mathrm{kg}\end{array}$ & $\begin{array}{c}\text { Nitrate, } \\
\mu M / \mathrm{kg}\end{array}$ & $\begin{array}{c}\text { Silicate, } \\
\mu M / \mathrm{kg}\end{array}$ \\
\hline \multicolumn{6}{|c|}{ A-1I, 109-1 Station $95\left(36^{\circ} 17^{\prime} 41^{\prime \prime} N, 10^{\circ} 02^{\prime} 27^{\prime \prime} W\right)$ Eastern North Atlantic } \\
\hline Surface & 36.545 & 230 & 0.01 & 0.20 & 1.34 \\
\hline 200 & 35.891 & 222 & 0.33 & 5.82 & 2.74 \\
\hline 500 & 35.651 & 198 & 0.81 & 13.97 & 6.56 \\
\hline 800 & 36.019 & 184 & 0.85 & 14.33 & 8.76 \\
\hline 1000 & 35.961 & 184 & 0.98 & 16.24 & 10.97 \\
\hline 1150 & 36.057 & 186 & 0.96 & 16.04 & 11.46 \\
\hline 1300 & 36.020 & 193 & 0.96 & 15.90 & 11.74 \\
\hline 2000 & 35.210 & 238 & 1.18 & 18.44 & 19.48 \\
\hline 3000 & 35.063 & 238 & 1.33 & 20.29 & 33.35 \\
\hline 4000 & 34.903 & 240 & 1.44 & 21.55 & 44.90 \\
\hline \multicolumn{6}{|c|}{ A-II, I09-1, Station $101\left(36^{\circ} 45^{\prime} 15^{\prime \prime} N, 08^{\circ} 36^{\prime} 20^{\prime \prime} W\right)$, Gulf of Cadiz } \\
\hline 650 & 36.587 & - & - & - & - \\
\hline \multicolumn{6}{|c|}{ A-II, 109-1, Station $30\left(36^{\circ} 15^{\prime} 38^{\prime \prime} N, 61^{\circ} 58^{\prime} 27^{\prime} W\right)$, Western North Atlantic } \\
\hline 200 & 36.523 & 224 & 0.11 & 3.06 & 1.59 \\
\hline 1100 & 35.063 & 218 & 1.08 & 19.69 & 13.39 \\
\hline 4850 & 34.896 & 263 & 1.24 & 18.97 & 35.59 \\
\hline
\end{tabular}

to and in the Mediterranean and the exchange of REE with the Atlantic. Therefore, we feel that a study of the Mediterranean outflow will give us insights to the influence it has on the REE distribution in the Atlantic Ocean and also on REE transport processes within the Mediterranean Sea. At certain locations the high-salinity character of the Mediterranean outflow allows easy identification of this water mass, making correlation of water samples with water source type definitive.

\section{Sampling and Analytical Procedures}

Seawater samples were collected for $\mathrm{Nd}$ isotopic analysis during cruise 109-1 of the RV Atlantis II from several locations along $36^{\circ} \mathrm{N}$ latitude. Samples reported in the present study are from three stations, two of which are from the vicinity of the Mediterranean outflow and one from the western basin. Sample locations are given in Table 1. Tenliter samples of seawater were collected from various depths in the water column, using Go-Flo and Nisken water sampling devices. The sampling depths were chosen on the basis of salinity profiles determined from CTD (conductivity, temperature, and depth) casts to insure a well-bracketed sampling of the Mediterranean outflow. Surface samples were collected in a plastic bucket from the bow of the ship. In an effort to minimize contamination of surface water surrounding the ship, the pumping of water from bilges and desalination plants was shut down prior to arrival on stations. Aliquots of the seawater samples were taken for the shipboard analysis of salinity, oxygen, and nutrient concentrations. The remainder of each sample was stored in polyethylene containers and acidified with $25 \mathrm{ml}$, high-purity 10 $\mathrm{N}$ HC1. All samples were analyzed for Nd isotopic composition and Sm and $\mathrm{Nd}$ concentration by using unfiltered 4-1 subsamples. The reagents, analytical techniques, and mass spectrometry have been described elsewhere [Piepgras et al., 1979].

\section{RESULTS}

Table 2 lists the results of hydrographic measurements of salinity, oxygen, and nutrients made on water samples collected for Sm and Nd analysis. Potential temperature $(\theta)$ and salinity $(S)$ data acquired from CTD measurements are plotted in $\theta-S$ diagrams in Figure 2 for all stations from which samples have been analyzed for $\mathrm{Sm}$ and $\mathrm{Nd}$. The $\theta-S$ diagram for station 95 (Figure $2 a$ ) contains two segments with nearly linear $\theta-S$ relationships. The first segment lies between the surface and about $500 \mathrm{~m}$. The second linear segment extends from $1200 \mathrm{~m}$ to the ocean bottom $(4700 \mathrm{~m})$. Between $500 \mathrm{~m}$ and $1200 \mathrm{~m}$, the $\theta-S$ diagram is characterized by a rather large increase in salinity from $35.656 \%$ to $36.148 \%$ and a relatively small drop in potential temperature from $11.4^{\circ} \mathrm{C}$ to $9.9^{\circ} \mathrm{C}$. This unique section of the $\theta-S$ diagram results from the addition of warm, saline waters flowing out from the Mediterranean Sea into the North Atlantic. Although the detailed structure between 500 and $1200 \mathrm{~m}$ shows some complexity, we will refer to samples lying within this interval as from the core of the Mediterranean outflow. From salinity considerations this core can be extended to about 1400 -m depth. The $\theta-S$ diagram for station 101 (Figure $2 b$ ) is similar to the upper portion of the $\theta-S$ diagram for station 95 . Potential temperature and salinity both decrease from the surface to a depth of about $400 \mathrm{~m}$ and then increase to the bottom. This increase in potential temperature and salinity below $400 \mathrm{~m}$ is interpreted as the result of outflowing Mediterranean water. There are four samples located within the Mediterranean core at station $95(800,1000,1150$, and $1300 \mathrm{~m})$ and one sample at station $101(650 \mathrm{~m})$.

Salinity and dissolved oxygen profiles generated from CTD measurements are shown in Figure 3. At station 95 (Figure 3a), salinity is observed to decrease from a surface maximum of $\sim 36.5 \%$ o to a value of $\sim 35.6 \%$ at $500 \mathrm{~m}$. Between $500 \mathrm{~m}$ and $1200 \mathrm{~m}$, salinity increases with maxima at 800 and $1200 \mathrm{~m}$ of $\sim 36.1 \%$. Below $1200 \mathrm{~m}$, the salinity decreases to the deepwater minimum value of $\sim 34.9 \%$ o. Dissolved oxygen shows a near-surface maximum of 271 $\mu M / \mathrm{kg}$ at $40 \mathrm{~m}$. It then decreases to a minimum of $1000 \mathrm{~m}$ of $178 \mu \mathrm{M} / \mathrm{kg}$. Below $1000 \mathrm{~m}$, dissolved oxygen values increase to a deepwater maximum of $249 \mu M / \mathrm{kg}$ at $2600 \mathrm{~m}$. Below this depth, the dissolved oxygen content remains nearly constant to the ocean bottom. The Mediterranean outflow is identified both by the salinity maxima between 500 and $1400 \mathrm{~m}$ and the oxygen minimum centered at $1000 \mathrm{~m}$. At station 101 (Figure $3 b$ ), salinity decreases from a surface maximum of $\sim 36.5 \%$ o to $\sim 35.7 \%$ at $400 \mathrm{~m}$. Below $400 \mathrm{~m}$, it increases to a bottom 

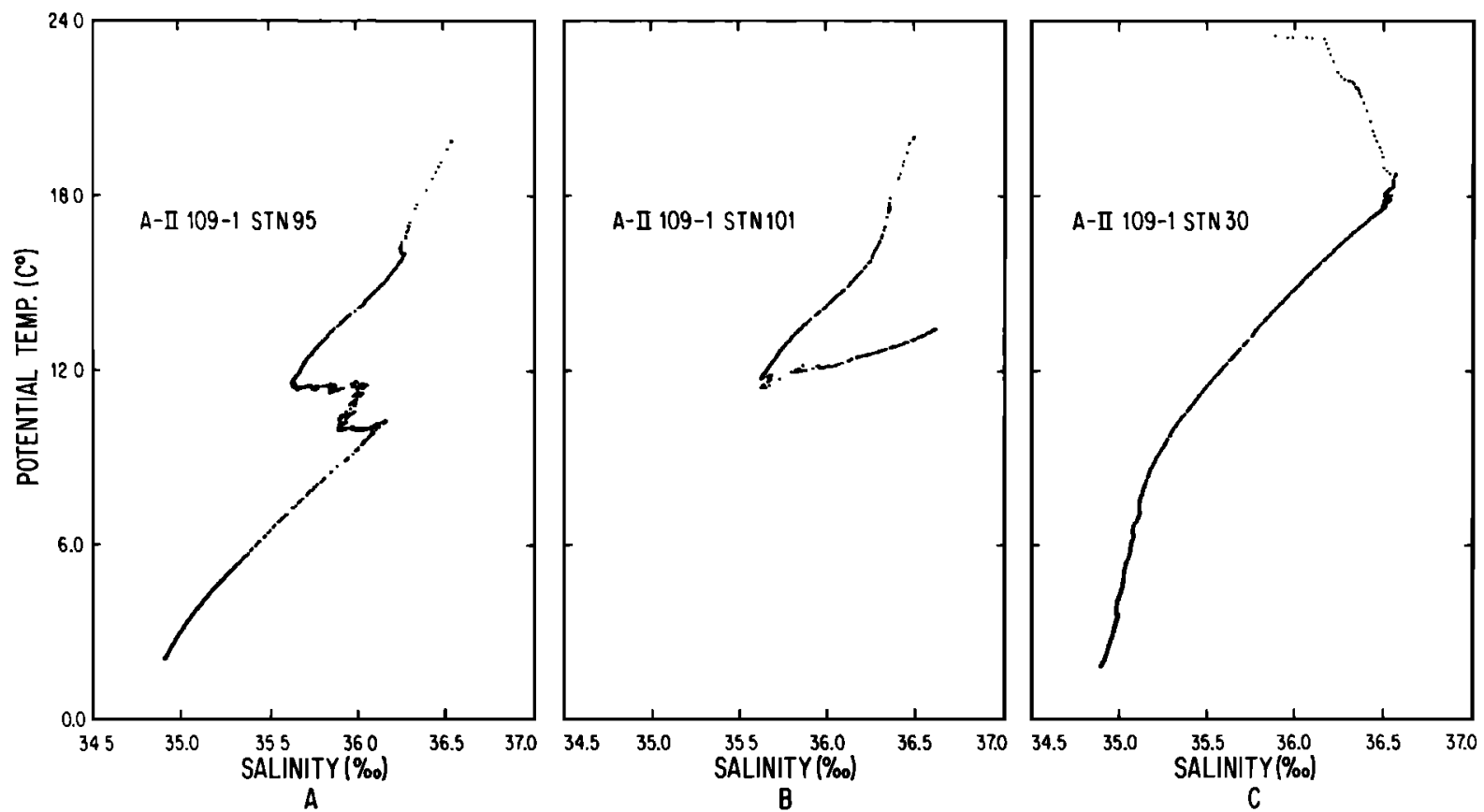

Fig. 2. Potential temperature vs. salinity at (A) station 95, (B) station 101 and (C) station 30 . The scale is the same for all three $\theta-S$ diagrams.

value of $\sim 36.6 \%$. This increase is a result of the Mediterranean outflow. The oxygen profile has a near-surface maximum at $40 \mathrm{~m}$ and then decreases to a bottom value of $\sim 194$ $\mu M / \mathrm{kg}$.

The nutrient concentrations for samples collected at station 95 are plotted in Figure 4. $\mathrm{PO}_{4}{ }^{3-}$ and $\mathrm{NO}_{3}{ }^{-}$increase rapidly with depth through the upper $500 \mathrm{~m}$ of the water column. Below $500 \mathrm{~m}$, they increase gradually to the bottom. Silicate maintains a fairly constant rate of increase at all levels in the water column. All of the nutrient profiles exhibit some perturbations in their concentration gradients at the level of the Mediterranean outflow.
Our results for $\mathrm{Sm}$ and $\mathrm{Nd}$ concentrations and $\mathrm{Nd}$ isotopic abundances are given in Table 1 . All of the isotopic results for station 95 are within the range of $\varepsilon_{\mathrm{Nd}}(0)$ values for the Atlantic Ocean that have been previously reported [Piepgras and Wasserburg, 1980]. The isotopic results for $\mathrm{Nd}$ at station 95 are plotted as a function of depth on Figure 5 . It is seen from inspection of Figure 5 that $\varepsilon_{\mathrm{Nd}}(0)$ varies with depth by $2.7 \varepsilon$ units. The top $500 \mathrm{~m}$ of the water column has $\varepsilon_{\mathrm{Nd}}(0)$ ranging from $-11.4 \pm 0.7$ to $-12.5 \pm 0.4$. Below $500 \mathrm{~m}$, $\varepsilon_{\mathrm{Nd}}(\mathbf{0})$ increases to more radiogenic values, reaching a maximum of $-9.8 \pm 0.6$ at $1000 \mathrm{~m}$. A repeat analysis of the 1000-m sample has $\varepsilon_{\mathrm{Nd}}(0)=-10.0 \pm 0.4$, indicating the

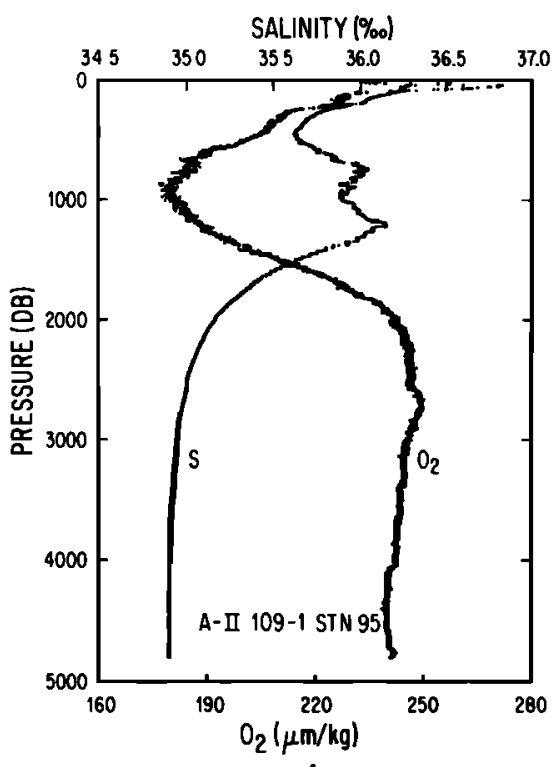

A

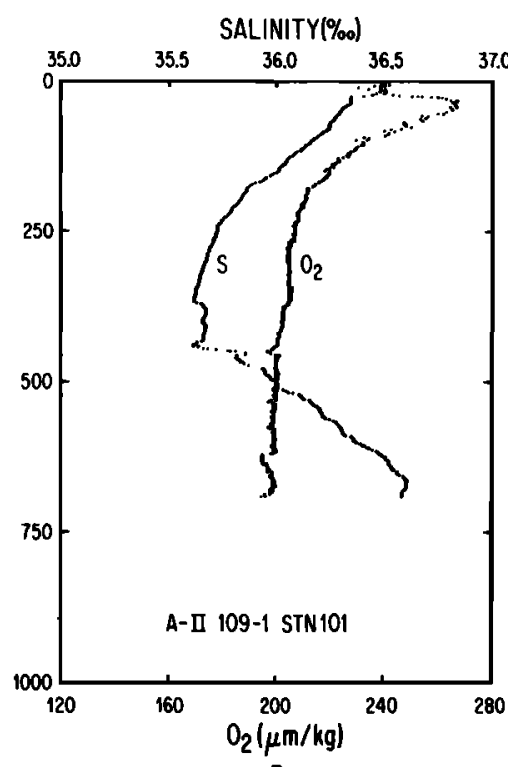

$B$

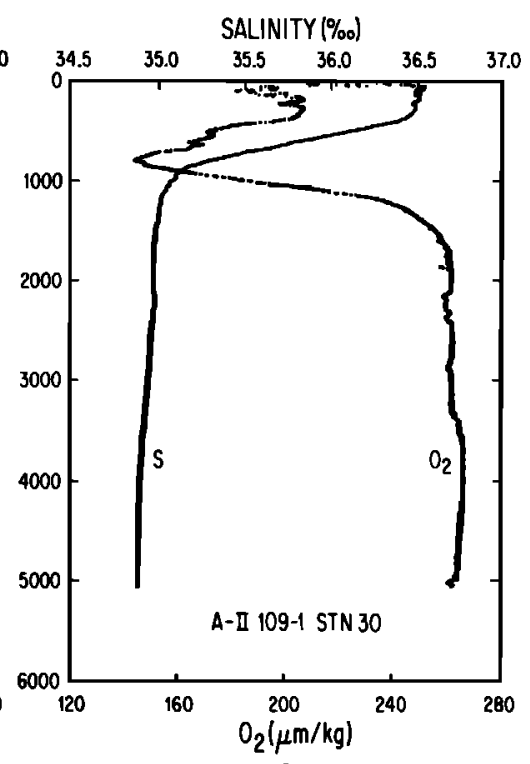

C

Fig. 3. Salinity and dissolved oxygen as a function of pressure (A) station 95 , (B) station 101 and (C) station 30 . The high-salinity tongue of the Mediterranean outflow is clearly seen in the profiles for stations 95 and 101 . 


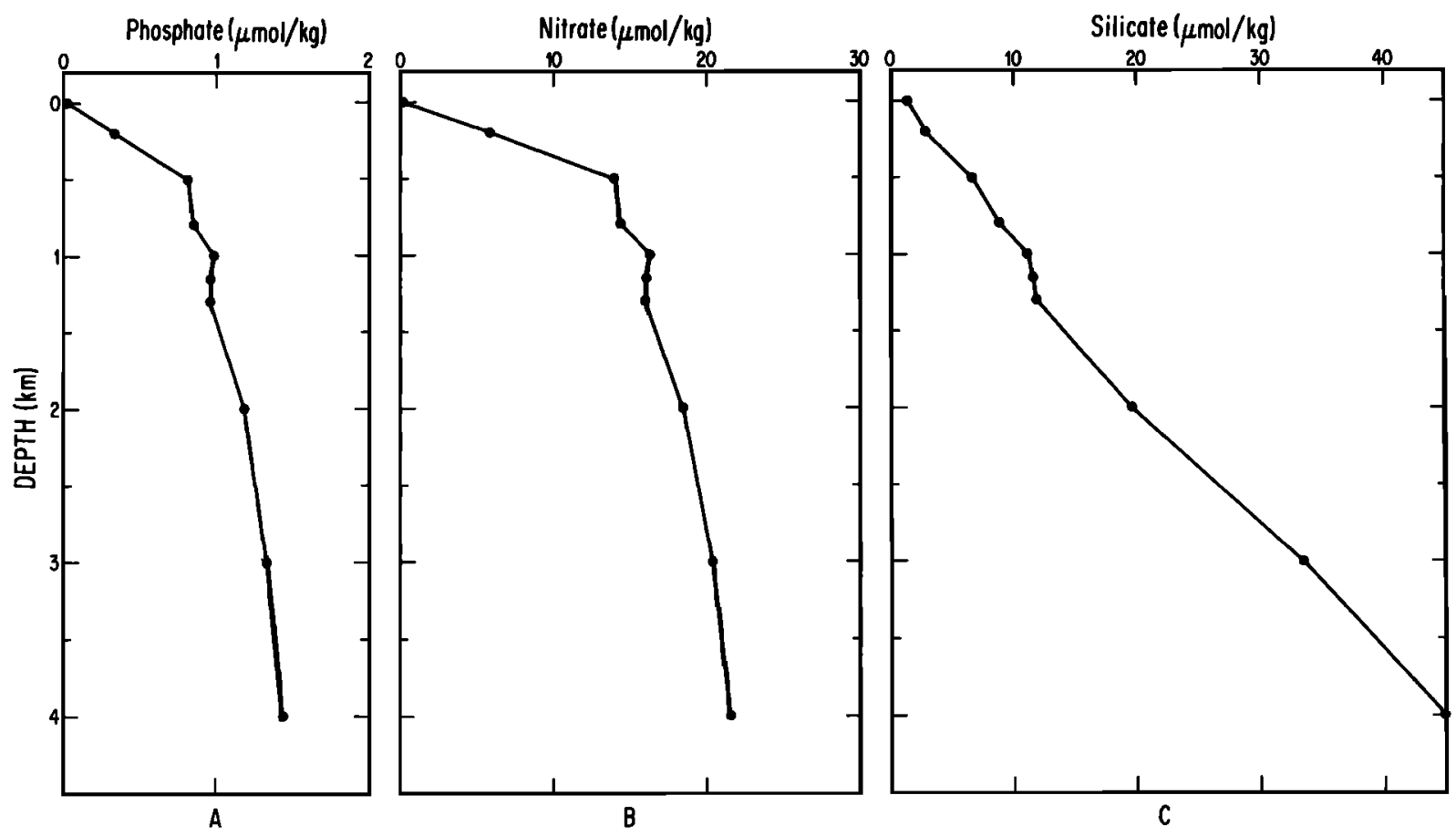

Fig. 4. Nutrient concentrations as a function of depth at station 95: (A) phosphate, (B) nitrate, and (C) silicate. The influence of the Mediterranean outflow can be observed on all of these profiles.

reproducibility of our methods. Below $1000 \mathrm{~m}, \varepsilon_{\mathrm{Nd}}(0)$ is lower again. At the $1150-\mathrm{m}$ depth, $\varepsilon_{\mathrm{Nd}}(0)=-11.7 \pm 0.5$ and remains nearly constant at this value to $4000 \mathrm{~m}$. One sample from station 101 at a depth of $650 \mathrm{~m}$ lies within the core of the Mediterranean outflow water and has $\varepsilon_{\mathrm{Nd}}(0)=-9.9 \pm 0.4$.

Results of $\mathrm{Sm}$ and Nd concentration measurements for station 95 are shown on Figure 6. In general the concentrations of both $\mathrm{Sm}$ and Nd increase with depth. The Nd concentration ranges from $1.80 \times 10^{-12} \mathrm{~g} / \mathrm{g}$ at the surface to $3.33 \times 10^{-12} \mathrm{~g} / \mathrm{g}$ at $4000 \mathrm{~m}$. Sm ranges between $0.375 \times 10^{-12}$ $\mathrm{g} / \mathrm{g}$ and $0.644 \times 10^{-12} \mathrm{~g} / \mathrm{g}$ in this depth interval. There are irregularities in this trend at depths between 800 and $2000 \mathrm{~m}$ where the concentrations of both $\mathrm{Sm}$ and $\mathrm{Nd}$ are observed to oscillate. Below $2000 \mathrm{~m}$, the $\mathrm{Nd}$ concentration exhibits an approximately linear increase with depth. Very little variation in the $\mathrm{Sm} / \mathrm{Nd}$ ratio is observed in the water column, as indicated by the nearly uniform ${ }^{147} \mathrm{Sm} /{ }^{144} \mathrm{Nd}$ ratios given in Table 1. The bottom sample from station 101 at $650 \mathrm{~m}$ has a high Nd concentration of $5.16 \times 10^{-12} \mathrm{~g} / \mathrm{g}$.

The $\theta-S$ diagram for station 30 is plotted in Figure $2 c$. Salinity is observed to increase with decreasing potential temperature until a salinity maximum of $\sim 36.5 \%$ is reached, which occurs between 50 and $200 \mathrm{~m}$ in the water column. Below the salinity maximum, both $\theta$ and $S$ decrease to the bottom. A slight bend in the $\theta-S$ curve below the salinity maximum indicates that a total of four components are involved in mixing at this location. For station 30, salinity and oxygen are plotted versus depth on Figure $3 c$. Salinity increases with depth to a broad, near-surface maximum between 50 and $200 \mathrm{~m}$ of $\sim 36.5 \%$. Below $200 \mathrm{~m}$, salinity decreases to the bottom. If Mediterranean outflow water were present, we would expect to see a salinity maximum at a depth of $\sim 1000$ to $1200 \mathrm{~m}$. However, this is not observed, and we conclude that there is no Mediterranean component at this westerly station. Oxygen has a near-surface maximum of $\sim 233 \mu M / \mathrm{kg}$ at $50 \mathrm{~m}$ and an intermediate-depth minimum of $\sim 145 \mu M / \mathrm{kg}$ at $\sim 800 \mathrm{~m} . \mathrm{O}_{2}$ then increases to $\sim 260 \mu M / \mathrm{kg}$ at $1800 \mathrm{~m}$. Below this depth, $\mathrm{O}_{2}$ is fairly uniform.

Nd concentrations and isotopic abundances for samples from station $\mathbf{3 0}$ are given in Table 1 . The isotopic data are presented in Figure $1 b$ and are almost indistinguishable from the observations in the Sargasso Sea. Nd at station 30

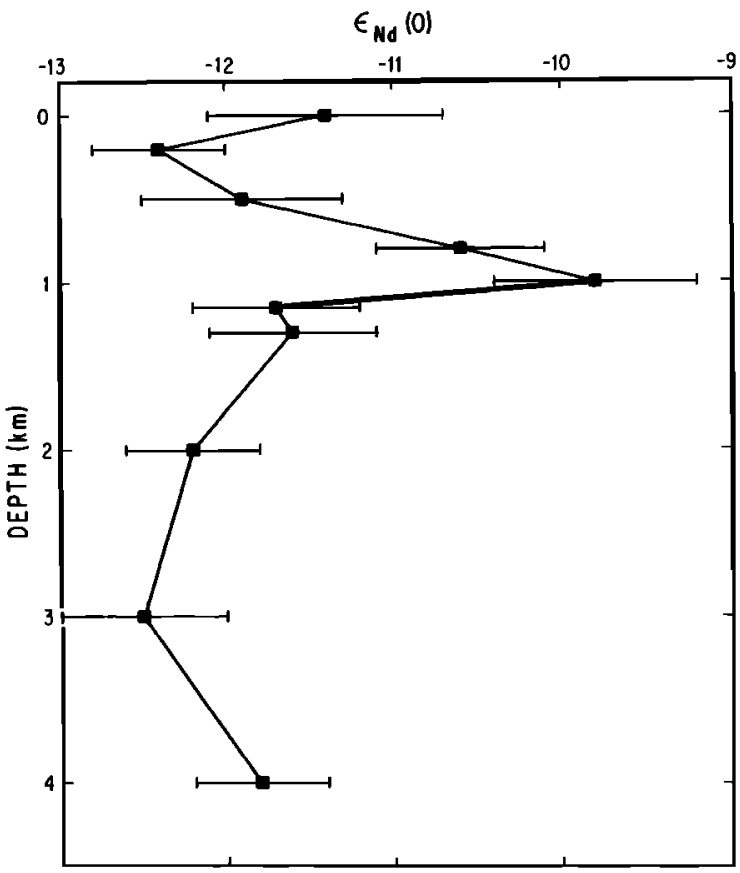

Fig. 5. $\varepsilon_{\mathrm{Nd}}(0)$ as a function of depth at station 95 in the eastern North Atlantic. Notice the maximum in $\varepsilon_{\mathrm{Nd}}(0)$ at $1000 \mathrm{~m}$. The error bars represent the $2 \sigma$ errors on the isotopic measurements. 


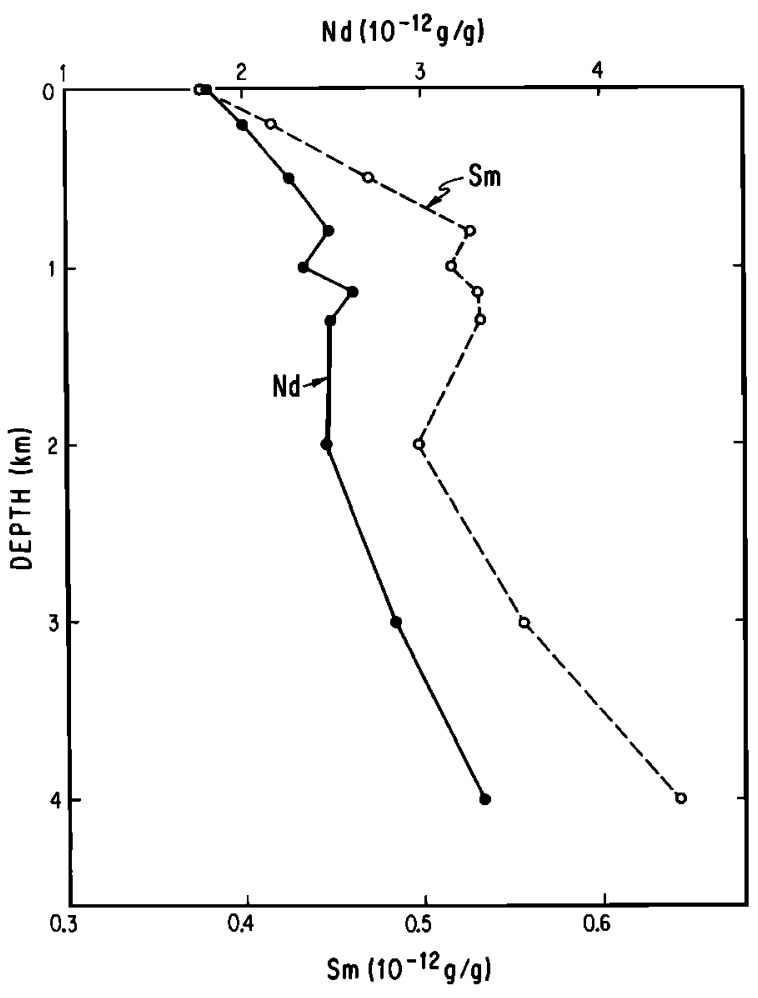

Fig. 6. Sm (open circles) and Nd (solid circles) as a function of depth at station 95 . Notice the similarity in the form of this curve in the depth region near $1000 \mathrm{~m}$ with that for salinity in Figure 5.

exhibits increasing concentration with depth. The bottom value of $9.01 \times 10^{-12} \mathrm{~g} / \mathrm{g}$ is the highest Nd concentration yet measured in ocean waters.

\section{Discussion}

The total range in $\varepsilon_{\mathrm{Nd}}(0)$ observed at station 95 is small; however, we find the shift in $\varepsilon_{\mathrm{Nd}}(0)$ toward more radiogenic values in two samples $(800 \mathrm{~m}$ and $1000 \mathrm{~m}$ ) associated with the core of the Mediterranean outflow to be significant. With the exception of the surface sample, the $2 \sigma$ errors on the 800 and $1000-\mathrm{m}$ samples do not overlap with those measurements at other depths, clearly indicating a source of $\mathrm{Nd}$ in these samples which is different from that in overlying and underlying waters. The maximum in $\varepsilon_{\mathrm{Nd}}(0)$ at $1000 \mathrm{~m}$, shown in Figure 5, correspond to approximately a 2- $\varepsilon$ unit shift from $\varepsilon_{\mathrm{Nd}}(0)$ values in overlying and underlying waters. We believe this shift to be a direct result of Mediterranean water having $\varepsilon_{\mathrm{Nd}}(0) \geq-9.8$ intruding into a nearly uniform layer of North Atlantic water having $\varepsilon_{\mathrm{Nd}}(0) \approx-12$. One sample from station $101(650 \mathrm{~m})$ in the Gulf of Cadiz represents Mediterranean outflow water as it is sinking down the continental slope. The value of $\varepsilon_{\mathrm{Nd}}(0)=-9.9 \pm 0.4$ in this sample is consistent with our conclusions about the source of the isotopic shift found at station 95.

Two samples $(1150 \mathrm{~m}$ and $1300 \mathrm{~m}$ ) associated with the Mediterranean core as defined by the $\theta-S$ diagram in Figure 2 have $\varepsilon_{\mathrm{Nd}}(0)=-11.7 \pm 0.5$ and $-11.6 \pm 0.6$, respectively. These values are similar to other deepwater values at this station. We find this surprising because these samples lie very close to the salinity maximum associated with the Mediterranean outflow. It is not clear why there should be an abrupt decrease in $\varepsilon_{\mathrm{Nd}}(0)$ below $1000 \mathrm{~m}$ while still being within the Mediterranean core, and we cannot explain this anomaly. Possibly, it is related to differences in the relative 'diffusion' rates of $\mathrm{Nd}$, temperature, and salinity. In principle, however, $\varepsilon_{\mathrm{Nd}}(0)$ can be decoupled from either temperature or salinity. This is because the isotopic composition of a mixture of two components is dependent on both the isotopic composition and $\mathrm{Nd}$ concentration of the end members being mixed. The relationship for the salinity $\left(S_{\mathrm{m}}\right)$ in a twocomponent mixture $\left(S_{1}\right.$ and $\left.S_{2}\right)$ is given by

$$
S_{\mathrm{m}}=X S_{1}+(1-X) S_{2}
$$

where $X$ is the weight fraction of component 1 in the mixture. For $\varepsilon_{\mathrm{Nd}}(0)$ the relationship is given by

$$
\varepsilon_{M}=\frac{X C_{1} \varepsilon_{1}+(1-X) C_{2} \varepsilon_{2}}{X C_{1}+(1-X) C_{2}}
$$

where the $C$ 's are the concentration per gram of $\mathrm{Nd}$ in the pure components. In a case, such as the Mediterranean outflow, where a high-salinity, low-Nd concentration component is mixing with a lower-salinity, higher-Nd component, it can be shown, from the above relationships, that $\varepsilon_{\mathrm{Nd}}(0)$ in mixtures of these components will initially approach the $\varepsilon_{\mathrm{Nd}}(0)$ value in the end member having the higher Nd concentration more rapidly than the salinity approaches
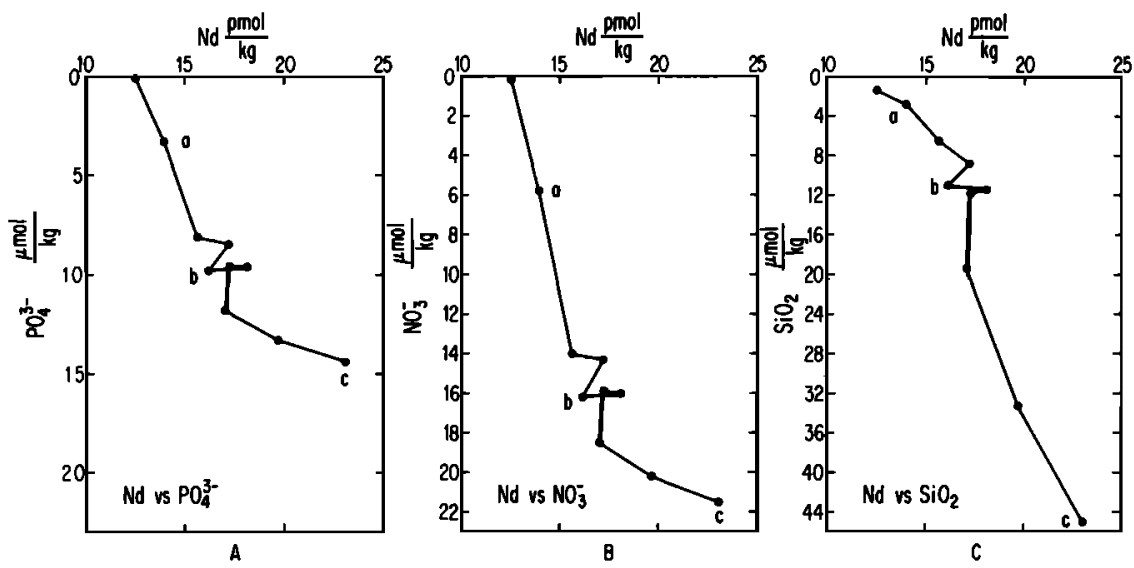

Fig. 7. Nd concentrations vs. (A) $\mathrm{PO}_{4}{ }^{3-}$, (B) $\mathrm{NO}_{3}{ }^{-}$, and (C) $\mathrm{SiO}_{2}$ for station 95 . For reference, the points labeled a, b, and $c$ correspond to the depths 200,1000 , and $4000 \mathrm{~m}$, respectively. 
the corresponding salinity end member. The Nd concentration difference in the end members at station 95 , however, is not sufficient to produce the decrease in $\varepsilon_{\mathrm{Nd}}(0)$ observed at $1150 \mathrm{~m}$. We do note that the data for station 30 are consistent with this explanation of the decoupling of salinity and $\varepsilon_{\mathrm{Nd}}(0)$.

Estimates of the proportion of the Mediterranean component in the outflow waters at station 95 can be made from the salinity data. At the depth of the salinity maximum in the eastern basin corresponding to the Mediterranean core, the western Atlantic basin has $S \approx 35 \%$. Using this value for a pure North Atlantic component, and taking $S=38.4 \%$ for the pure Mediterranean component [Dietrich et al., 1980], we estimated, from the salinity corresponding to the maximum in $\varepsilon_{\mathrm{Nd}}(0)$ at station 95 , an $\sim 30 \%$ Mediterranean component in the outflow core. Another method for estimating the fraction of Mediterranean water present is the conservative tracer 'NO' ('NO' $=\mathrm{O}_{2}+9 \mathrm{NO}_{3}{ }^{-}$) [Broecker and Takahashi, 1980]. From this approach we also calculate an $\sim 30 \%$ Mediterranean component in the outflow at station 95 , which agrees with that calculated from the salinity.

Although we have not made a direct measurement of $\mathrm{Nd}$ in Mediterranean water, it is possible to estimate its Nd isotopic composition. The Mediterranean component is diluted primarily by North Atlantic surface water $\left(\varepsilon_{\mathrm{Nd}}(0)=-11.4\right.$ at station 95), which enters the Mediterranean through the Straits of Gibraltar. If the core of the Mediterranean outflow at station 95 has about a 30\% Mediterranean component, with the remaining component being primarily North Atlantic surface water, and assuming approximately equal Nd concentrations, then this would imply that pure Mediterranean component would have $\varepsilon_{\mathrm{Nd}}(0) \sim-6$. Elderfield and Greaves [1982] analyzed a sample of biogenic carbonate from the Mediterranean and found $\varepsilon_{\mathrm{Nd}}(0)=-7.1$; this supports our estimate for $\varepsilon_{\mathrm{Nd}}(0)$ in the Mediterranean Sea. However, it is not a direct determination, and since our estimates of the proportions of pure Mediterranean water at station 95 could be in error, measurements of $\mathrm{Nd}$ in Mediterranean waters must be made to determine the actual composition. This has not yet been possible because of the lack of availability of expeditions.

The water budget of the Mediterranean Sea is dominated by the influx of Atlantic water, yet the Nd isotopic results reported here clearly indicate a source of Nd in the Mediterranean with an isotopic composition that differs from the Atlantic. Using a box model to describe the steady state conditions for $\mathrm{Nd}$ in the Mediterranean, we have

$$
\begin{gathered}
O=C_{\mathrm{A}} \dot{W}_{\mathrm{AM}}-C_{\mathrm{M}} \dot{W}_{\mathrm{MA}}+J_{C}-J_{S} \\
O=C_{\mathrm{A}} \varepsilon_{\mathrm{A}} \dot{W}_{\mathrm{AM}}-C_{\mathrm{M}} \varepsilon_{\mathrm{M}} \dot{W}_{\mathrm{MA}}+J_{C} \varepsilon_{C}-J_{S} \varepsilon_{\mathrm{M}}
\end{gathered}
$$

where the subscript $A$ represents the Atlantic and $M$ the Mediterranean. The $C$ 's are concentrations of Nd; the $\varepsilon$ 's are the isotopic compositions; $\dot{W}_{i j}$ represents the volume rate of water flow between the Atlantic and Mediterranean in the directions indicated by the subscripts; $J_{S}$ is a sink term for $\mathrm{Nd}$ in the Mediterranean; and $J_{C}$ is the net flux of Nd into the Mediterranean from sources other than the Atlantic that are characterized by isotopic compositions $\varepsilon_{C}$. It can be seen from (4) and (5) that if $J_{C}=0$ then $\varepsilon_{\mathrm{A}}=\varepsilon_{\mathrm{M}}$ and there would be no difference in the isotopic composition of $\mathrm{Nd}$ in the Mediterranean from the Atlantic. There is a difference observed, however, indicating that $J_{C}$ is nonzero. Solving (4) for $J_{S}$, and substituting this result into (5), we have

$$
J_{C}=\frac{\left(\varepsilon_{\mathrm{A}}-\varepsilon_{\mathrm{M}}\right)}{\left(\varepsilon_{\mathrm{M}}-\varepsilon_{C}\right)} C_{\mathrm{A}} \dot{W}_{\mathrm{AM}}
$$

For estimating $J_{C}$ we will use data from Tchernia [1980] for our estimates of the Mediterranean water budget. We can put reasonable limits on $\varepsilon_{C}$. Since $\varepsilon_{M}>\varepsilon_{A}$, it follows that $\varepsilon_{C}$ $>\varepsilon_{M}$. A strict upper limit for $\varepsilon_{C}$ must be $\sim+12$, a high value for midocean ridge basalts. If we assume $\varepsilon_{\mathrm{A}} \approx-12, \varepsilon_{\mathrm{M}} \approx$ $-7, C_{\mathrm{A}} \approx 2 \times 10^{-12} \mathrm{~g} / \mathrm{g}$, and $\dot{W}_{\mathrm{AM}}=1.11 \times 10^{6} \mathrm{~m}^{3} / \mathrm{s}$, then using the above limits for $\varepsilon_{C}, J_{C} \geqslant 0.58 \mathrm{~g} \mathrm{Nd} / \mathrm{s}$. It is reasonable to assume that $\mathrm{Nd}$ concentrations in the Black Sea would be of the same order of magnitude as oceanic concentrations. Therefore, the flux of Nd from the Black Sea inflow of $6.35 \times 10^{3} \mathrm{~m}^{3} / \mathrm{s}$ should be negligible in comparison to the total flux $J_{C}$. If all of the Nd that had $\varepsilon_{C}$ were supplied by runoff $\left(1.11 \times 10^{4} \mathrm{~m}^{3} / \mathrm{s}\right)$, then the dissolved concentration of $\mathrm{Nd}$ in these waters must be greater than $\sim 53 \times 10^{-12} \mathrm{~g} / \mathrm{g}$. This is close to the value for dissolved concentrations levels of $\sim 40 \times 10^{-12} \mathrm{~g} / \mathrm{g}$, measured for river waters by Martin and Maybeck [1980]. However, negative values of $\varepsilon_{\mathrm{Nd}}(0)$ seem more likely for continental drainages. For example, North American shale has $\varepsilon_{\mathrm{Nd}}(0)=-14.4$ [DePaolo and Wasserburg, 1976]. Data from Goldstein and O'Nions [1982] for river-suspended loads have $\varepsilon_{\mathrm{Nd}}(0)=-9.3$ to -16.2 . Data by M. Stordal (personal communication, 1982) for both suspended and dissolved loads in the Mississippi River have $\varepsilon_{\mathrm{Nd}}(0) \sim-12$. These values of $\varepsilon_{\mathrm{Nd}}(0)$ in continental drainages are clearly too negative to produce the appropriate isotopic value in the Mediterranean required by our data. If we considered a high value of $\varepsilon_{\mathrm{Nd}}(0)=-3$ for the continental drainages into the Mediterranean $\left(\varepsilon_{C}\right)$, then the $\mathrm{Nd}$ concentration in the continental runoff must be $\sim 250 \times$ $10^{-12} \mathrm{~g} / \mathrm{g}$. If instead of the calculated value for $\varepsilon_{M}$ we assume that our observed value of -9.8 for $\varepsilon_{\mathrm{Nd}}(0)$ in the Mediterranean outflow represents the lowest possible value in undiluted Mediterranean water, then for $\varepsilon_{C} \leqslant+12, J_{C} \geqslant 0.22 \mathrm{~g}$ $\mathrm{Nd} / \mathrm{s}$, and the dissolved concentration in runoff must be $\geqslant 20$ $\times 10^{-12} \mathrm{~g} / \mathrm{g}$. A lower value of $\varepsilon_{C}=-6$ would result in a runoff concentration of $\sim 115 \times 10^{-12} \mathrm{~g} / \mathrm{g}$. The negative values of $\varepsilon_{C}$ used in the above two cases yield runoff concentrations for $\mathrm{Nd}$ that are high in comparison to the river water values given by Martin and Maybeck. However, the present data base for REE in river waters is small, so this apparent discrepancy may not be real. Such values for $\varepsilon_{C}$ in runoff would indicate that rivers in this region are draining a young continental terrane possibly characterized by a late Precambrian basement ( $T \leq 0.9 \mathrm{Ae}$ ) and younger volcanic terranes. If $\varepsilon$ values in runoff were much more negative than the $\varepsilon_{C}$ values used in the two cases above, excessively high concentrations of $\mathrm{Nd}$ in the runoff would be required. This would require a source of $\mathrm{Nd}$ additional to that of continental drainages. One possible source may be the injection of $\mathrm{Nd}$ remobilized from volcanogenic deep-sea sediments in the Mediterranean basin. Volcanic ash layers are common in eastern Mediterranean sediments [Ryan, 1971] and could represent a source of soluble and relatively radiogenic $\mathrm{Nd}$ necessary to shift the isotopic composition of incoming Atlantic water. Direct measurements of Nd in major drainages into the Mediterranean are needed to determine the relative importance of sources.

The deepwater $\varepsilon_{\mathrm{Nd}}(0)$ values at station 95 (Figure 5) 
contrast with those from the western basin of the North Atlantic. The values of -13 to -14 in the western Atlantic (Figure $1 a, b)$ are significantly lower than the $\varepsilon_{\mathrm{Nd}}(0)$ values of $\sim-12$ in the deep layer at station 95 . On the basis of $\mathrm{Nd}$ isotopic signatures alone, the deep waters of the eastern and western basins of the Atlantic Ocean thus appear to be distinguishable. The low values of $\varepsilon_{\mathrm{Nd}}(0)$ in the deep waters are assumed to be a feature of North Atlantic deep water [Piepgras and Wasserburg, 1980]. If the source of North Atlantic deep water were the same for both the eastern and western basins, then one might expect that the isotopic composition of $\mathrm{Nd}$ associated with this water mass should be identical in both basins. The difference in isotopic composition implies that subsequent to the formation of North Atlantic deep water there have been modifications in the deep waters of the eastern and western basins that have resulted in a divergence of their isotopic characters. Presumably, injection of waters having distinctive isotopic compositions results in the eastern basin having more radiogenic values of $\varepsilon_{\mathrm{Nd}}(0)$ than the western basin. At present, it is not possible to determine whether only one or both basins have undergone modification, or if North Atlantic deep water represents a unique or homogenous source. We note, however, that the $\varepsilon_{\mathrm{Nd}}(0)$ value in the Mediterranean outflow $\left(\varepsilon_{\mathrm{Nd}}(0)=-9.8\right)$ could be considered a possible source of radiogenic $\mathrm{Nd}$ for modifying the eastern basin values. The more radiogenic $\varepsilon$ values in the eastern basin may also be, in part, due to a larger southern component (Antarctic bottom water) than found in the western basin. A southern component would have $\varepsilon_{\mathrm{Nd}}(0) \approx-9$ [Piepgras and Wasserburg, 1982]. Broecker [1979] suggested using $\mathrm{SiO}_{2}$ or 'NO' for estimating the magnitude of the southern component. The proportion of a southern component, as determined from $\mathrm{SiO}_{2}$, is as high as $\sim 40 \%$ in the deepest waters, compared with $\sim 30 \%$ as determined from 'NO.' Eastern basin silicate values may be anomalously high, however, because of silica dissolution [Broecker and Takahashi, 1980]. As sampled during this cruise, no difference in 'NO' values is observed between deep waters in the eastern and western basins. It is therefore not clear what influence Antarctic bottom water has on the isotopic differences observed between the eastern and western basins. The isotopic differences may also reflect a difference in the mean isotopic compositions of the sediments between the eastern and western basins if injections of REE from sediments into overlying waters are considered as an important source of these elements in the oceans.

The isotopic signature we attribute to the Mediterranean outflow $\left(\varepsilon_{\mathrm{Nd}}(0)=-9.8\right)$ at $1000 \mathrm{~m}$ is indistinguishable from the maximum in $\varepsilon_{\mathrm{Nd}}(0)$ in the near-surface waters of the Sargasso Sea $\left(\varepsilon_{\mathrm{Nd}}(0)=-9.6\right)$ and at station $30\left(\varepsilon_{\mathrm{Nd}}(0)=\right.$ -9.4). It is clear from the differences in depth in the water column at which these maxima are observed that the source of the relatively radiogenic $\mathrm{Nd}$ in the surface waters of the western basin is different from that observed for the Mediterranean outflow at station 95 . The near-surface maxima in the western basin suggest that $\mathrm{Nd}$ of this isotopic composition is being transported by the Gulf Stream system. The presence of different sources of REE having the same $\mathrm{Nd}$ isotopic character indicates that we must be cautious in identifying water masses on the basis of Nd isotopic characteristics alone.

Sm and Nd concentrations at station 95 are shown in Figure 6. The general trend in the concentration profiles is toward higher concentration with increasing water depth. While there is no apparent relationship between $\mathrm{Sm}$ and Nd concentrations and $\mathrm{Nd}$ isotopic compositions in the water column here, like $\varepsilon_{\mathrm{Nd}}(0)$, these concentration profiles are influenced by the Mediterranean outflow. In the core of this outflow the Sm and Nd concentrations appear to imitate the salinity in that they oscillate with the highs in the $\mathrm{Sm}$ and $\mathrm{Nd}$ concentrations corresponding to the high-salinity portions of the curve and the lows corresponding to lower salinity. Outside the region of the Mediterranean core, $\mathrm{Sm}$ and $\mathrm{Nd}$ increase in concentration downward in an approximately linear manner. Except within the core of Mediterranean water, the concentration gradient reported here is similar to concentration profiles measured in other parts of the world ocean [Piepgras and Wasserburg, 1982]. The presence of a concentration gradient requires some type of particle transport to deplete the surface and enrich the deep waters. The nature of these particles and the mechanism by which they transport REE have not been identified, and they require further study. A general discussion of vertical transport on sequestering particles and redissolution has been given by Piepgras and Wasserburg [1982]. It should be made clear, however, that the isotopic data require a source of $\mathrm{Nd}$ in the deep waters in addition to that transported from the surface on settling particles.

Elderfield and Greaves [1982] have measured REE concentrations for filtered seawater in a profile from the eastern North Atlantic, located at approximately $28^{\circ} \mathrm{N}, 26^{\circ} \mathrm{W}$ in a region that is also influenced by the Mediterranean outflow. However, they did not report any Nd isotopic composition data for these waters. Comparison of their Sm and Nd data with ours for station 95 show the profiles to be very similar, but in general the concentration levels at our station are 2030\% lower at comparable depths than reported by Elderfield and Greaves; ${ }^{147} \mathrm{Sm} /{ }^{144} \mathrm{Nd}$ ratios at these two localities also differ. Calculated ${ }^{147} \mathrm{Sm} /{ }^{144} \mathrm{Nd}$ ratios from the data of Elderfield and Greaves range from 0.106 to 0.126 , with the exception of one sample $(200 \mathrm{~m})$ that has ${ }^{147} \mathrm{Sm} /{ }^{144} \mathrm{Nd}=$ 0.173 . By comparison, our ${ }^{147} \mathrm{Sm} /{ }^{144} \mathrm{Nd}$ ratios vary between 0.117 and 0.134 , with no outlying values. One notable exception to the similarity in the $\mathrm{Sm}$ and $\mathrm{Nd}$ concentration profiles of these two stations is the surface enrichments of Sm and Nd, reported by Elderfield and Greaves. We find no eivdence of a surface enrichment of Sm and Nd at station 95, but rather the surface has the lowest concentrations. The reasons for this difference are not known but may be related to higher levels of dust fallout from the Sahara at their station, as suggested by Elderfield and Greaves. Alternatively, the difference between the surface concentrations of these two stations could be a result of the collection and filtration methods used. The lessons learned from lead studies in seawater [Patterson, 1974] have clearly demonstrated the problem of sample contamination during collection of water samples for trace metal analysis, especially in the surface waters surrounding a ship on station. We believe the levels of contamination for the REE are far below those observed for elements like $\mathrm{Pb}, \mathrm{Cu}$, and $\mathrm{Zn}$, which are widely used industrially. We have carried out our sampling and analytical procedures with considerable care and believe that the regularity of our results indicate that they are not reasonably due to contamination. Nonetheless, the potential for contamination effects should always be considered when interpreting any trace element data in seawater. 
Comparison of $\mathrm{Nd}$ concentrations versus nutrient concentrations provides an indication of a source of dissolved Nd from bottom sediments. The transport of many trace elements in the deep sea is often correlated with nutrient profiles [see Bruland, 1980, for several examples]. Increases in nutrient concentrations with depth are believed to be associated with the dissolution of settling particles [Bruland, 1980]. Thus a positive linear correlation between a trace element and nutrients implies that the same processes act to transport the correlated species. Samples from station 95 were analyzed for nutrient concentrations to compare directly with $\mathrm{Sm}$ and $\mathrm{Nd}$ concentration levels; $\mathrm{Nd}$ vs. $\mathrm{PO}_{4}{ }^{3-}$, $\mathrm{NO}_{3}{ }^{-}$, and $\mathrm{SiO}_{2}$ are plotted in Figure 7. The upper $500 \mathrm{~m}$ of the water column show an approximately linear correlation between nutrient levels and Nd concentrations, as indicated in Figure 7. From the strong correlation in the upper portions of the water column between Nd and nutrients it can be argued that the same processes are acting to transport the REE through the water column. Samples within the Mediterranean outflow core ( 800 to $1300 \mathrm{~m})$ do not exhibit a linear correlation between $\mathrm{Nd}$ and nutrients. This is probably a result of complex mixing processes between core waters and surrounding waters. There is a marked change in slope of Nd versus either $\mathrm{PO}_{4}{ }^{3-}$ (Figure 7a) or $\mathrm{NO}_{3}{ }^{-}$(Figure $7 b$ ) in the deep waters below the Mediterranean outflow relative to waters above the outflow. A linear correlation is still observed in these samples, however. The change in slope below the Mediterranean core is a result of there being a relatively greater rate of increase with depth in the concentration of $\mathrm{Nd}$ as compared to $\mathrm{PO}_{4}{ }^{3-}$ or $\mathrm{NO}_{3}{ }^{-}$in the deep waters. Injection of REE remobilized from deep-sea sediments seems the most likely source of this 'excess' $\mathrm{Nd}$ in the deep waters, although it could imply a more rapid depletion of nutrients relative to the REE in the particulate phase during dissolution of settling particles in the deep waters. For Nd versus $\mathrm{SiO}_{2}$ (Figure 7c) there is also a change in slope below the Mediterranean core. In this case, however, $\mathrm{SiO}_{2}$ concentrations are found to increase in relation to $\mathrm{Nd}$, indicating a source of 'excess' silica relative to $\mathrm{Nd}$ in the deep waters. The higher silica values in the deep water could be the result of larger southern ocean contributions to the dissolved silica budget in the eastern basin of the North Atlantic relative to the western basin. Resolution in the deep ocean of silica tests having very low Nd concentrations may also be indicated. In either case the deep waters of the eastern basin appear to have a different source of REE from that in overlying shallower waters. This observation is compatible with the idea that deep-sea sediments represent a source of REE in the deep ocean. Laterally transported Nd in bottom currents having high Nd concentrations may also be a source of this deep-water excess.

The source of relatively nonradiogenic Nd in the deep waters of the North Atlantic remains to be determined. Two possibilities are runoff from Precambrian terranes into the Arctic Ocean and mobilization of REE in deep-sea sediments. Based on data for composite samples from the Canadian Shield [McCulloch and Wasserburg, 1978], runoff from Archean terranes would be expected to have $\varepsilon_{\mathrm{Nd}}(0) \lessgtr$ -25. If freshwater injections from North America and Asia into the Arctic are characterized by such low values of $\varepsilon_{\mathrm{Nd}}(0)$, then this component should be easily identified in Arctic Ocean waters. A northerly source for Nd associated with North Atlantic deep water would require extensive lateral transport of $\mathrm{Nd}$ in the North Atlantic and would indicate that bottom currents are supplying the 'excess' $\mathrm{Nd}$ to the deep waters.

REE could be supplied to the deep waters by injection from deep-sea sediments having $\mathrm{Nd}$ that is isotopically less radiogenic than that presently being supplied at the near surface of the oceans. This process has already been suggested as an important source of copper in the deep ocean [Craig, 1974; Boyle et al., 1977]. These workers argue that scavenging takes place at all levels in the water column, and therefore a source of copper at the bottom is required to maintain the higher concentrations in the deep waters. This argument can also be made for Nd and other REE, since they display concentration gradients similar to those found for copper. We have already presented evidence from Nd concentrations vs. nutrient correlations for a deepwater source of Nd. Lateral as well as vertical transport is most evident from the difference in isotopic composition between deep and surface waters observed at many locations, which may also indicate a deepwater source of $\mathrm{Nd}$. In addition, arguments can be made for the injection of $\mathrm{Nd}$ from sediments from mass balance considerations. Based on concentrations of $40 \mathrm{ng} / \mathrm{kg}$ of $\mathrm{Nd}$ dissolved in rivers [Martin and Maybeck, 1980] and a net annual discharge of $4.6 \times 10^{19}$ cc/yr [Holland, 1978], a residence time of $\sim 2200$ years is obtained with respect to river input. This residence time is too long to be compatible with $\mathrm{Nd}$ observations in the oceans. In order to maintain the observed $\mathrm{Nd}$ isotopic variations in the oceans, we estimate that the oceanic REE residence times must be on the order of a few hundred years or less. From Elderfield and Greaves [1982] the residence time is $\sim 750$ years with respect to atmospheric dust input. This assumes that all of the $\mathrm{Nd}$ in the dust is soluble, which we believe is unlikely. If $10 \%$ of the atmospheric Nd were soluble, an $\sim 7500$-year residence time is indicated. Goldstein and $O$ 'Nions [1982] analyzed dust samples from the eastern Atlantic and western Pacific and found a limited range of isotopic composition from $\varepsilon_{\mathrm{Nd}}(0)=-9.1$ to -10.1 . These values are too radiogenic to be the source of deepwater Nd. This further indicates that atmospheric dust may only be of local importance as a source of REE in the oceans. All of these considerations strongly indicate that a source of dissolved Nd from bottom sediments may be necessary to bring the dissolved oceanic REE budget into balance. However, Nd isotopic data from Goldstein and $O$ 'Nions [1981] for Atlantic deep-sea sediments exhibit a wide range of $\varepsilon_{\mathrm{Nd}}(0)$ from -3.4 to -12.3 . Most of their values for Atlantic sediments are much more radiogenic than in overlying waters and in typical Atlantic Fe-Mn nodules. This would indicate that deep-sea sediments are not the source of $\mathrm{Nd}$ in the deep Atlantic waters, unless differential dissolution of older continental components can occur. We conclude that while the dominantly continental nature of $\mathrm{Nd}$ in ocean waters is well established, the detailed sources of Nd in the oceans are not yet established, and we are not yet able to identify and assess the importance of processes active at the sediment-seawater interface that may affect the REE budget of the oceans.

\section{Conclusions}

Nd isotopic results presented here have established that the outflow of Mediterranean water into the Atlantic is characterized by a shift in isotopic composition correspond- 
ing to $\varepsilon_{\mathrm{Nd}}(0) \geq-9.8$ for Mediterranean waters. This outflow is seen as a shift toward more radiogenic values of ${ }^{143} \mathrm{Nd} /$ ${ }^{144} \mathrm{Nd}$ in the water column of the eastern North Atlantic at a water depth of $1000 \mathrm{~m}$ relative to overlying and underlying waters that have $\varepsilon_{\mathrm{Nd}}(0) \approx-12$. This shift of two $\varepsilon$ units coincides with the core of the Mediterranean outflow as identified from salinity measurements. We estimate the isotopic composition of Mediterranean water to be $\varepsilon_{\mathrm{Nd}}(0) \approx$ -6 to -7 . The source of Nd with this isotopic composition may be runoff from a relatively young continental terrane or injection of $\mathrm{Nd}$ from deep-sea sediments that have significant young volcanogenic components. Though the Nd isotopic component of water associated with the Mediterranean outflow is indistinguishable from that in the near-surface waters of the western Atlantic, we have concluded that they must reflect different sources of $\mathrm{Nd}$.

The deep waters from the eastern basin of the North Atlantic are isotopically distinguishable from the deep waters in the western basin. This may indicate inhomogeneity in the North Atlantic deep water sources or modification of waters in the eastern and/or western basins subsequent to the formation of this water mass. If Nd in the deep waters is supplied from sediments, the isotopic differences between the eastern and western basins could reflect sediments that have an 'older' $\mathrm{Nd}$ component in the western basin relative to the eastern basin.

The bulk of waters in the North Atlantic are characterized by lower values of $\varepsilon_{\mathrm{Nd}}(0)(-11.5$ to -14.0$)$, indicating that there must be a major source of REE injections we have not identified. The source of $l o w^{143} \mathrm{Nd} /{ }^{144} \mathrm{Nd}$ in the North Atlantic deep water may be runoff from Precambrian shields of North America and Asia into the Arctic Ocean, or possibly injection of the REE from some old component in bottom sediments into the overlying water column.

Comparison of $\mathrm{Nd}$ concentration data with corresponding nutrient data for station 95 has been made. Linear correlations between $\mathrm{Nd}$ and $\mathrm{PO}_{4}{ }^{3-}, \mathrm{NO}_{3}{ }^{-}$, and $\mathrm{SiO}_{2}$, respectively, are observed in waters above and below the Mediterranean outflow core. On the basis of a difference in slope of these correlations above and below the outflow core, we have concluded that there is a source of 'excess' Nd in the deep waters at this station. We suggest that the source of this 'excess' $\mathrm{Nd}$ is the injection of REE from deep-sea sediments into the overlying water column.

Acknowledgments. We thank C. Wunsch and M. S. McCartney for providing ship time in the Atlantic. We appreciate the cooperation of the crew of the RV Atlantis II during the collection of the samples. B. Lowman and J. Jennings performed the nutrient analyses. This study has benefited greatly from many discussions with $\mathbf{M}$. Stordal. We would also like to thank T. Takahashi and C. G. H. Rooth for their suggestions on improving the manuscript. This research was supported by grant NSF OCE-8108595. Basic labora- tory operations were supported by NASA NGL-05-002-188. This is contribution 3803 (425) of the Division of Geological and Planetary Sciences, California Institute of Technology.

\section{REFERENCES}

Boyle, E. A., F. Sclater, and J. M. Edmond, The distribution of dissolved copper in the Pacific, Earth Planet. Sci. Lett., 37, 38S4, 1977.

Broecker, W. S., A revised estimate for the radiocarbon age of North Atlantic Deep Water, J. Geophys. Res., 84, 3218-3226, 1979.

Broecker, W. S., and T. Takahashi, Hydrography of the Central Atlantic-3, The North Atlantic deep-water complex, Deep-Sea Res., 27A, 591-613, 1980.

Bruland, K. W., Oceanographic distributions of cadmium, zinc, nickel, and copper in the North Pacific, Earth Planet. Sci. Lett., 47, 176-198, 1980.

Craig, H., A scavenging model for trace elements in the deep sea, Earth Planet. Sci. Lett., 23, 149-159, 1974.

DePaolo, D. J., and G. J. Wasserburg, Nd isotopic variations and petrogenetic models, Geophys. Res. Lett., 3, 249-252, 1976.

Deitrich, G., K. Kalle, W. Krauss, and G. Sielder, General Oceanography: An Introduction, 2nd ed., John Wiley, New York, 1980.

Elderfield, H., and M. J. Greaves, The rare earth elements in seawater, Nature, 296, 214-219, 1982.

Goldstein, S. L., and R. K. O'Nions, $\mathrm{Nd}$ and $\mathrm{Sr}$ isotopic relationships in pelagic clays and ferromaganese deposits, Nature, 292 , 324-327, 1981 .

Goldstein, S. L., and R. K. O'Nions, Nd isotopic study of river particulates, atmospheric dusts, and pelagic sediments (abstract), Eos Trans. AGU, 63, 352-353, 1982.

Holland, H. D., The Chemistry of the Atmosphere and Oceans, John Wiley, New York, 1978.

Jacobsen, S. B., and G. J. Wasserburg, Sm-Nd isotopic evolution of chondrites, Earth Planet. Sci. Lett., 50, 139-155, 1980.

Knauss, J. A., Introduction to Physical Oceanography, PrenticeHall, Englewood Cliffs, New Jersey, 1978.

Martin, J. -M., and M. Maybeck, Elemental mass-balance of material carried by major world rivers, Mar. Chem., 7, 173-206, 1980.

McCulloch, M. T., and G. J. Wasserburg, Sm-Nd and Rb-Sr chronology of continental crust formation, Science, 200, 1003$1011,1978$.

Patterson, C. C., Lead in seawater, Science, 183, 553-554, 1974.

Piepgras, D. J., and G. J. Wasserburg, Neodymium isotopic variations in seawater, Earth Planet. Sci. Lett., So, 128-138, 1980.

Piepgras, D. J., and G. J. Wasserburg, Isotopic composition of neodymium in waters from the Drake Passage, Science, 217, 207214, 1982.

Piepgras, D. J., G. J. Wasserburg, and E. J. Dasch, The isotopic composition of $\mathrm{Nd}$ in different ocean masses, Earth Planet. Sci. Lett., 45, 223-236, 1979.

Ryan, W. B. F., Stratigraphy of Late Quarternary sediments in the eastern Mediterranean, in The Mediterranean Sea: A Natural Sedimentation Laboratory, edited by D. J. Stanley, pp. 149-169, Dowden, Hutchinson and Ross, Stroudsburg, Pa., 1971.

Tchernia, P., Descriptive Regional Oceanography, Pergamon, New York, 1980.

(Received September 20, 1982; revised March 14, 1983; accepted March 15, 1983.) 